\title{
Numerical and experimental studies in the development of new clothing materials
}

\author{
E. L. Correia ${ }^{1}$, S. F. C. F. Teixeira ${ }^{1} \&$ M. M. Neves ${ }^{2}$ \\ ${ }^{1}$ Department of Production and Systems, University of Minho, Portugal \\ ${ }^{2}$ Department of Textile Engineering, University of Minho, Portugal
}

\begin{abstract}
In order to enhance the quality and added value of their products, Portuguese industry must react to consumer demands. Amongst the main criteria, thermal comfort is becoming a pressing issue. Such new requirements open new fields in research and development, in which computer simulation plays an important role. In the present work a transient model for heat and mass transfer in a fabric, which is a simplified version of the Gibson and Carmachi model, has been implemented. In order to make the model user friendly, a software application has been developed. This makes it easier to introduce the input data and visualize the results. In parallel, new materials made from natural fibres have been used to produce new knitting. Their thermal properties have been measured in the laboratory and were used to validate the numerical model. The model can be integrated into a wider model for the thermal regulation of the human body. Such a tool could be very useful for designing new fabrics for clothing applications.

Keywords: thermal human comfort, heat and mass transfer, numerical models, new clothing materials, computer interface, physiological comfort.
\end{abstract}

\section{Introduction}

People tastes and concerns have changed over time. Nowadays, customers tend to give less importance to the technical specifications of the fabrics used for clothing and focus more on their appearance and handling characteristics. Wear comfort of clothing is presently one of the major concerns for customers. But it is also a very broad concept, as it involves all the aspects of comfort. It is a balanced mix of psychological, physiological and sensorial comfort [1]. 
The wear comfort is given mostly by the fabrics specifications both functional (related to the physiological and sensorial comfort) as aesthetics (related to the psychological comfort). The aesthetics specifications are the domain of the textile designers and they must satisfy the cultural and social environment of the user, its individuality and fashion trends. The textile design engineer is responsible for the functional specifications.

To achieve higher quality products with a greater added value, European producers must respond to the consumer needs, and new demands of wear comfort opened a wide variety of areas to look into as well as, new fields in research and development.

The present work is part of a wider effort [2-4] to couple experimental data with numerical tools for the development and testing of functional knitting.

\section{Numerical model and interface}

Mathematical modelling of the clothing materials has been developed [5-8] and it is a valuable tool to understand the complex mechanisms of the coupled heat and moisture transfer.

\subsection{Mathematical equations}

In order to simulate the transient behaviour of simultaneous heat and moisture transfer in a fabric, a simplified version of Gibson and Chamarchi [5] model has been implemented in the present work. The model includes effects such as heat and mass diffusion through the fabric thickness and also, the sorption phenomena. There is no liquid phase present and the model does not include gas or liquid phase convection in the fabric but it assumes heat convection to the environment. Two partial differential equations are solved for the temperature and vapour density.

One of the governing equations is the energy equation, eqn. (1):

$$
\rho c_{p} \frac{\partial T}{\partial t}=\frac{\partial}{\partial x}\left(k_{e f f} \frac{\partial T}{\partial x}\right)-\left(Q_{L}+\Delta h_{v a p}\right) \dot{m}_{s v}
$$

which includes the transient term in the left side and those on the right hand side are, respectively, the diffusion and sorption.

The energy equation is coupled with the gas phase diffusion equation, eqn. (2), which models the phenomena associated with water vapour component:

$$
\varepsilon_{\gamma} \frac{\partial}{\partial t}\left(\rho_{v}\right)=\frac{\partial}{\partial x}\left(D_{e f f} \frac{\partial \rho_{v}}{\partial x}\right)+\dot{m}_{s v}-\rho_{v} \frac{\partial}{\partial t}\left(\varepsilon_{\gamma}\right)
$$

The transient term appears on the left hand side of eqn (2) and the first term on the right hand side describes the diffusion transfer $\left(D_{\text {eff }}\right.$ is the effective gas phase diffusivity), the second term accounts for the mass rate of desorption from solid phase to vapour phase and the last term describes the changes of the volume fraction $\left(\varepsilon_{\gamma}\right)$ occupied by the gas phase (air and water vapour) in the 
control volume. Apart from the gas, the dry solid fibre and the water bounded in the solid phase occupy the remaining part of this volume. In consequence, $\rho$ (density), $c_{p}$ (heat capacity) and $k_{\text {eff }}$ (effective thermal conductivity) are average properties depending on the volume fraction of each component (air, water, vapour and fibre) and they had to be updated in each time step.

The source term in eqns (1) and (2) due to the vapour sorption is modelled assuming that the material at the fibre surface immediately come into equilibrium with the relative humidity of the gas phase at that point, and so, the mass flux into and out the fibre is calculated by:

$$
\dot{m}_{s v}=\frac{D_{\text {solid }} \rho_{d s}}{d_{f}^{2}}\left(R_{\text {total }}-R_{\text {skin }}\right)
$$

which depends on the difference between the instantaneous fibre regain and the equilibrium regain at relative humidity.

The two partial differential equations, eqns (1) and (2), constitute a system of parabolic equations which are solved in time and space. They can be integrated to obtain the temperature and water vapour concentration profiles in the fabric thickness and along the time, after knowing the initial conditions $(T(x, t=0)$ and $\left.\rho_{v}(x, t=0)\right)$ and the boundary conditions at each side of the fabric thickness for temperature and vapour density.

Numerical methods have been used to integrate the system of parabolic equations. The finite volume method (Versteeg and Malalasekera [9]) has been used for space integration and an implicit scheme was used in time integration.

Because the temperature is also a function of the vapour density, an iterative scheme has been implemented. At each step in time, the temperature field is calculated assuming a given water vapour concentration in all control volumes across the fabric thickness; with this new temperature profile the vapour density field is calculated; the physical properties are updated and a new temperature field is calculated and this iterative process is repeated until convergence is achieved. More details on the mathematical model, algorithm and numerical solution can be found in Correia [10].

\subsection{Computer interface}

Considering the large amount of physical constants in the model and in order to make the model user friendly, a software application to store all this information and visualise results has been developed. Using a computer interface, the user can introduce the numerical parameters and to choose the fabric to be tested.

The interface TECIDOS was designed in Pascal (Delphi 6) for Windows environment and it allows four main menus: numerical parameters; fabric choice; simulation (Fig. 1) and way out.

In the menu "numerical parameters", the user can choose the time integration step and the total time for simulation as well the results precision. Then, the user can select from a large database a natural fibre and run the numerical code to 
obtain the main results at the screen. At the moment, the user will have access to temperature and vapour concentration profiles as well as the amount of water in the fabric at each time step.

The application includes also a menu to leave the application and return to the main system.

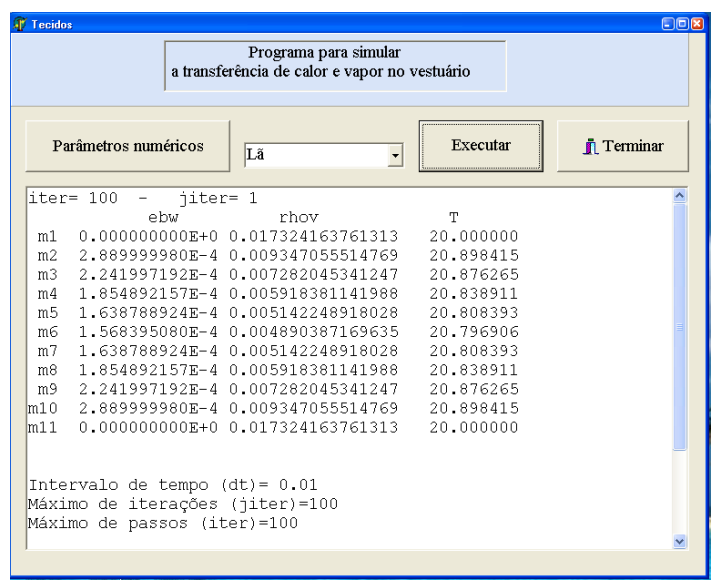

Figure 1: Main page of the interface.

\section{Experimental results}

The raw materials were selected in order to provide the better combination of the following properties: humidity transport, anti bacteria resistance, hypo allergic ability, low thermal conduction. Some ecological considerations were also taken into account: how fibres were produced and recycling possibilities at the end of its life.

Thus, the following raw materials were selected: hydrophilic fibres (cotton, corn, soybean and bamboo) and hydrophobic fibres (polypropylene and polyester). Table 1 shows the different raw materials and yarn count used for knitting production.

These raw materials were used to produce knitting in order to validate the numerical model.

Double face knitting was also produced and is now being characterized. The design of double face knitting tries to answer the questions of humidity transport and maintenance of optimal temperature of the foot, avoiding the formation of micro organisms/fungi.

The application of this knitting must contribute, in a substantial way, for an increase in comfort, removing the humidity released by skin and reducing the heat exchange with the environment.

To achieve this performance, different structures and raw materials were used. Three double face-knitting structures with eight different combinations of raw materials, in a total of twenty-four samples were made. The different 
knitting structures, with the hydrophilic fibre on one side and the hydrophobic fibre on the other, are shown in table 2.

Table 1: $\quad$ Raw materials.

\begin{tabular}{|l|l|l|}
\hline Raw Material & Designation & Yarn Count \\
\hline $100 \%$ Cotton & CO & $30 / 1 \mathrm{Ne}$ \\
\hline $100 \%$ Corn & PLA & $30 / 1 \mathrm{Ne}$ \\
\hline $100 \%$ Soybean & SPF & $30 / 1 \mathrm{Ne}$ \\
\hline $100 \%$ Bamboo & BAM & $30 / 1 \mathrm{Ne}$ \\
\hline $100 \%$ Polypropylene & PP & $200 \mathrm{dtex}$ \\
\hline $\begin{array}{l}85 \% \text { Polyester, } 15 \% \\
\text { Cotton }\end{array}$ & $85 \%$ PES, $15 \% \mathrm{CO}$ & $60 / 2 \mathrm{Ne}$ \\
\hline
\end{tabular}

Table 2: $\quad$ Knitting structures.

\begin{tabular}{|c|c|c|}
\hline 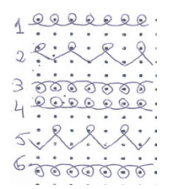 & 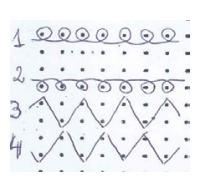 & 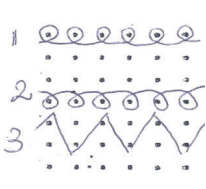 \\
\hline Structure 1 & Structure 2 & Structure 3 \\
\hline
\end{tabular}

The 8 different hydrophilic/hydrophobic fibres combinations to produce the 24 samples, at the loom, were PLA/PP, PLA/PES, SPF/PP, SPF/PES, BAM/PP, $\mathrm{BAM} / \mathrm{PES}, \mathrm{CO} / \mathrm{PP}$ and $\mathrm{CO} / \mathrm{PES}$.

After the production, each sample was characterized and some properties are currently being evaluated. For the thermo physiological comfort, the following critical properties are suggested: thermal resistance, air permeability, water vapour permeability and liquid water permeability.

To evaluate the air permeability of the different samples, the TEXTEST FX 3300 permeability meter and the EN ISO 9237 standard (100 Pa of pressure) were used. The knitting samples produced with structure 1 and combination PLA/PES have higher permeability than the others.

The water vapour permeability of materials is an important property to maintain the thermal equilibrium of the user. It is one of the parameters that have a bigger contribution for the textile thermal physiological comfort. The experiments were made with the PERMETEST permeability meter and according ISO 11092 (see Fig. 2).

The samples with higher values were made with structure 1 and combinations PLA/PES, SPF/PES and BAM/PES.

A thermal manikin robot is being used for thermal resistance evaluation. 


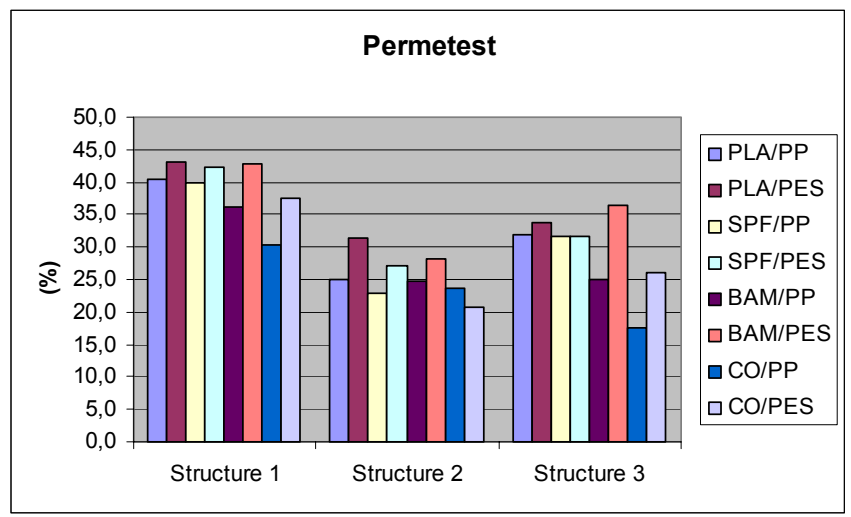

Figure 2: Water vapour relative permeability.

\section{Numerical results}

The knitting made from natural fibres was tested with the numerical model and some results are now presented.

Two different types of fibres can be compared in terms of water retain: a natural hydrophilic fibre (cotton) and a hydrophobic fibre (polyester).

The number of control volumes across the knitting thickness and the time integration step, have been changed and optimal values have been obtained.

The model sensitivity to the physical properties was tested in special, the convective heat and mass transfer coefficients. These parameters have been investigated [11] because of the results dependence on their values.

Two different environments have been considered. Firstly, the dry fabrics with initial temperature of $20^{\circ} \mathrm{C}$ were placed into contact with a relative humidity of $100 \%$ and at the ambient temperature of $20^{\circ} \mathrm{C}$. With this test, the temperature change due to the water vapour entrance into the fibres can be observed.

Fig. 3 shows the temperature profile along the cotton knitting thickness for three different times $(10,150$ and $3600 \mathrm{~s})$. The knitting thickness is $0.75 \times 10^{-3} \mathrm{~m}$ and the grid points $\mathrm{ml}$ and $\mathrm{m} 11$ are the boundaries (ambient conditions at each side of the knitting).

It can be observed the expected symmetry. Because cotton fibre is hydrophilic, as soon as, the sorption of water vapour occurs, the temperature rises uniformly across the fabric thickness. Then, evaporation takes place and the temperature decreases again until it reaches the ambient temperature. The amount of water dissolved in the fabric fibres, along the time ( $\left.\rho_{v} d \varepsilon_{b w} / d t=-\dot{m}_{s v}\right)$, can also be calculated. The water vapour entrance will continue until the equilibrium regain is achieved (Fig. 4).

The polyester knitting is also tested with the same boundary conditions. The dry knitting of $1.1 \times 10^{-3} \mathrm{~m}$ thickness and initial temperature of $20^{\circ} \mathrm{C}$ is placed into contact with a relative humidity of $100 \%$. 


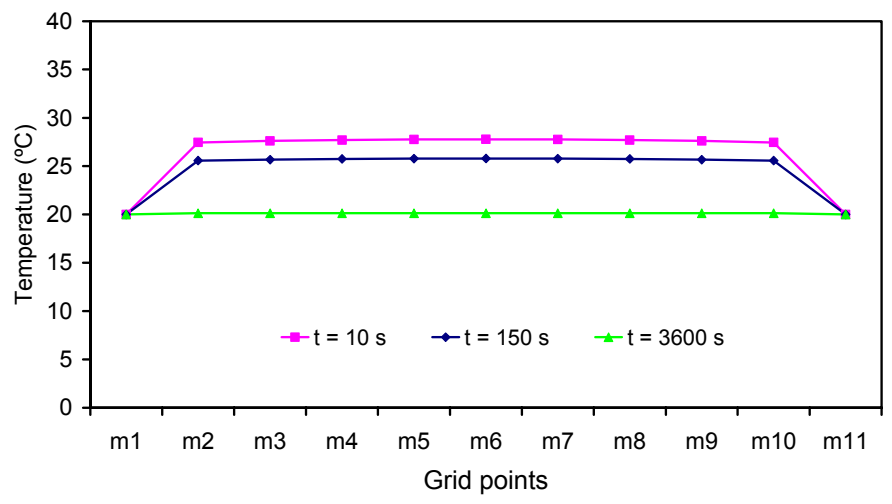

Figure 3: Numerical temperature profile across cotton knitting thickness for different times.

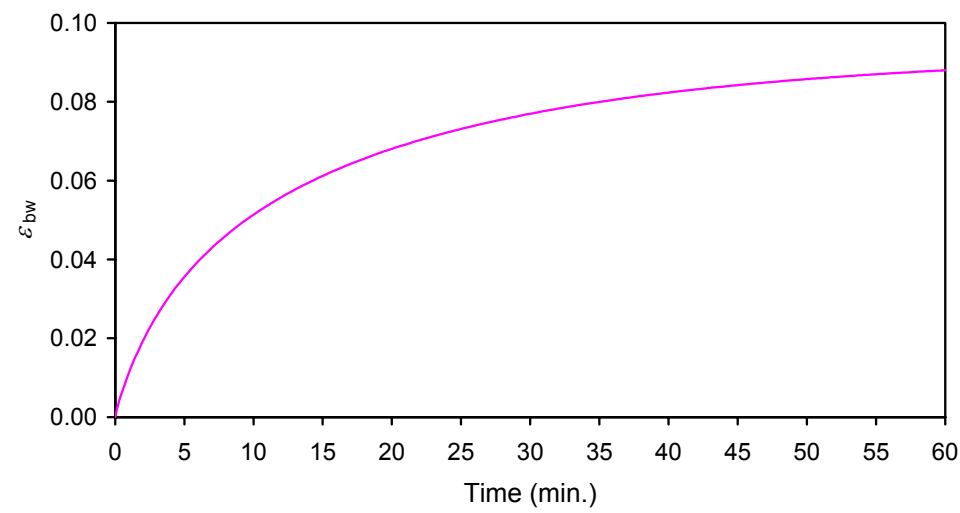

Figure 4: Volume fraction of water at the centre point of the cotton knitting.

Because polyester fibre is hydrophobic, the temperature rise due to the sorption mechanism is smaller (Fig. 5) compared with the cotton fabric case (Fig. 3).

The fabric made of hydrophilic fibre (cotton) was then tested with a different set of boundary conditions as more suitable to the knitting application: one side of the knitting is usually with contact with the human body skin (at $32^{\circ} \mathrm{C}$ and with some moisture $-\mathrm{m} 1$ ) and the other side in contact with the environment (an atmosphere of $20^{\circ} \mathrm{C}$ and a relative humidity of $65 \%-\mathrm{m} 11$ ). Such imbalance yields non-symmetry in the volume fraction of water profile (Fig. 6), after a $10 \mathrm{~s}$ period.

The water vapour concentration along the knitting thickness is illustrated in Fig. 7 . 
296 Advanced Computational Methods in Heat Transfer IX

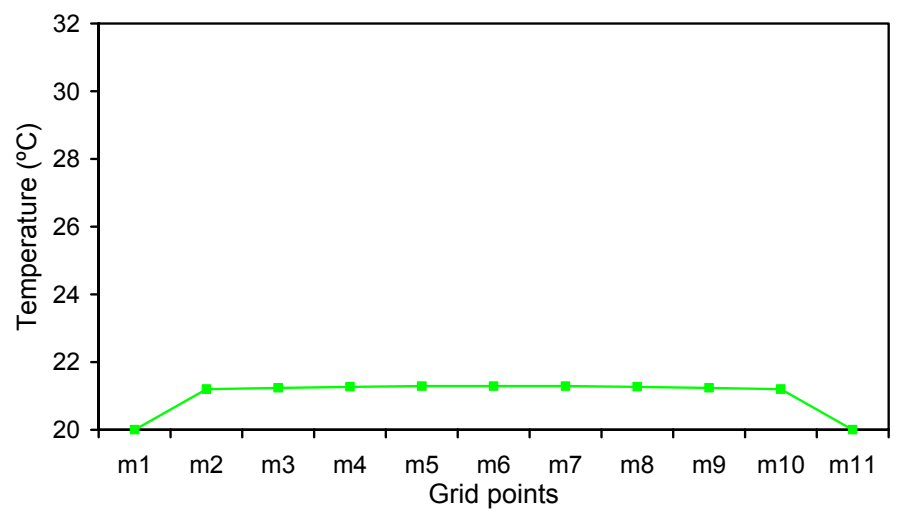

Figure 5: Temperature profile for polyester knitting after $10 \mathrm{~s}$.

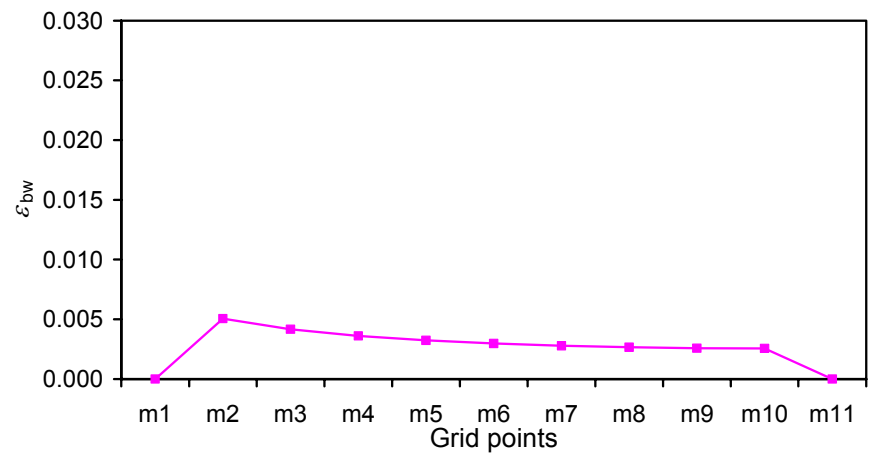

Figure 6: Volume fraction of water dissolved into the cotton fibres across the knitting thickness after $10 \mathrm{~s}$ contact.

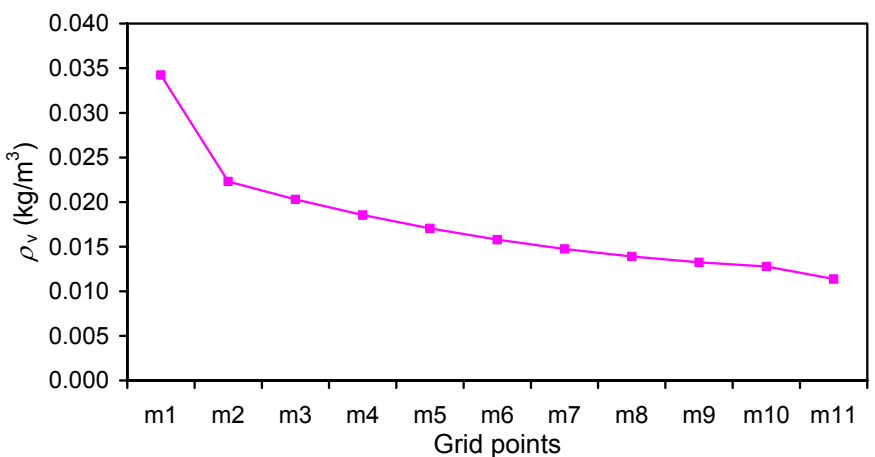

Figure 7: Water vapour concentration profile along the thickness. 


\section{Conclusions}

A computer application was developed in order to correctly model the heat and mass transfer phenomena across the knitting thickness.

Some experimental work has been taken in order to produce double face knitting, which will contribute in a substantial way, to an increase in the human physiological comfort.

Further work will extend the numerical model to simulate these functional knitting and integrate a thermal regulation of the human body [12-14] and it will be applicable to the design of new clothing applications.

\section{Acknowledgment}

The authors would like to acknowledge the financial support from the Portuguese Foundation for the Science and Technology (FCT) through the research project POCTI/EME/62786/2004.

\section{References}

[1] Fourt, L. \& Hollies, N. R. S., Clothing: Comfort and Function, Marcel Dekker, Inc., New York, USA, 1970.

[2] Teixeira, S.F.C.F., Ferreira, M.L. \& Costa, L.G., A Computer interface for human comfort calculations. Proceedings of IMC22, 31 Ago-2 Set, p. 131-137, 2005.

[3] Neves, M. \& Cunha, J., Total design of function oriented textile product, 5th International Istanbul Textile Conference, Istanbul, Turkey, May 2005.

[4] Epifânio, P., Silva, A., Teixeira S.F.C.F. \& Teixeira, J.C.F., Modelo de conforto térmico baseado na distribuição da temperatura do corpo humano. Métodos Numéricos en Ingeniería $V$ (CD-ROM), SEMNI, Espanha, 2002.

[5] Gibson, P.W. \& Chamarchi, M., Modelling convection/diffusion processes in porous textiles with inclusion of humidity-dependent air permeability. Int. Comm. Heat Mass Transfer, 24(5), pp. 709-724, 1997.

[6] Kwon, A., Kato, M., Kawamura, H., Yanai, Y. \& Tokura, H., Physiological significance of hydrophilic and hydrophobic textile materials during intermittent exercise in humans under the influence of warm ambient temperature with and without wind. Eur. J. Appl. Physiol., 78, pp. 487-493, 1998.

[7] Fan, J., Luo, Z. \& Li, Y., Heat and moisture transfer with sorption and condensation in porous clothing assemblies and numerical simulation. International Journal of Heat and Mass Transfer, 43, pp. 2989-3000, 2000.

[8] Chang, W. \& Weng, C., An analytical solution to coupled heat and moisture diffusion transfer in porous materials. International Journal of Heat and Mass Transfer, 43, pp. 3621-3632, 2000. 
[9] Versteeg, H.K. \& Malalasekera, W., An Introduction to Computational Fluid Dynamics, the Finite Volume Method, Longman Scientific \& Technical, 1995.

[10] Correia E. L., Modelo Térmico Aplicado à Caracterização do Conforto Proporcionado pelo Vestuário, MSc Thesis, University of Minho, 1995.

[11] Dear, R.J., Arens, E., Hui, Z. \& Oguro, M., Convective and radiative heat transfer coefficients for individual human body segments. Int. J. Biometeorol, 40, pp. 141-156, 1997.

[12] Berger, X. \& Sari, H., A new dynamic clothing model. Part 1: Heat and mass transfers. Int. J. Therm. Sci., 39, pp. 635-645, 2000.

[13] Ghaddar, N., Ghali, K. \& Jones, B., Integraded human-clothing system model for estimating the effect of walking on clothing insulation. International Journal Thermal Sciences, 42, pp. 605-619, 2003.

[14] Salloum, M., Ghaddar, N. \& Ghali, K., A new transient bio-heat model of the human body. Proc of HT2005, ASME Summer Heat Transfer Conference, July 17-22, San Francisco, USA, 2005. 